\title{
Performances Multimídia: análise de exemplos e implicações conceituais
}

\author{
Marcus Vinicius Fainer Bastos ${ }^{1}$ \\ https://orcid.org/0000-0001-6786-7993 \\ Patrícia Moran Fernandes" \\ https://orcid.org/0000-0001-5663-9207 \\ I - Pontifícia Universidade Católica de São Paulo. \\ São Paulo (SP). Brasil. \\ II - Universidade de São Paulo. \\ São Paulo (SP). Brasil.
}

Resumo: $O$ artigo analisa performances multimídia realizadas entre os anos 1970 e 1990, que exploram elementos da estrutura da ópera e as possibilidades de montagem espacial no ambiente do palco. O texto parte de uma contextualização sobre os desafios à leitura crítica do audiovisual experimental - especialmente dos eventos - como consequência da constante mudança terminológica com o surgimento de novas tecnologias, impactando o campo conceitual e as poéticas. Em seguida, procura organizar o repertório crítico constituído em torno dos diálogos entre a ópera e a performance multimídia, examinando de que forma as propostas recentes sobre as articulações intermídia se inserem na profícua e plural tradição da ópera. Por fim, o texto dedica-se à análise de obras deste universo, especialmente à produção de José Roberto Aguilar, Arrigo Barnabé e Décio Pignatari em parceria com Lívio Tragtenberg e Wilson Sukorski.

Palavras-Chave: intermídia; montagem espacial; performance audiovisual multimídia.

Abstract: Multimedia performance: analysis of examples and conceptual implications - The paper proposes an analysis of multimedia performances 
presented between the 1970s and the 1990s, which explore elements of the opera structure and explore the possibilities of spatial montage allowed by the stage environment. The text starts with a contextualization on the challenges that are presented to the critical analysis of experimental audiovisual - specially events - as a consequence of the constant terminological change with the appearance of new technologies impacting the conceptual field and its poetics. Then, it seeks to organize the critical repertoire constituted around the dialogues between opera and multimedia performance, examining how the most recent thoughts on intermedia articulations of language are part of the fruitful and plural tradition of opera. Finally, the text focus on the analysis of significant works from this universe, with a closer look at the production of artists such as José Roberto Aguilar, Arrigo Barnabé and Décio Pignatari in partnership with Lívio Tragtenberg and Wilson Sukorski.

Keywords: intermedia; spatial montage; audiovisual multimedia performance.

\section{Introdução}

Os anos 1980, especialmente no Brasil, representam uma época de deslocamentos da trajetória das linguagens audiovisuais mais experimentais. Em ondas no início e em meados do século XX, o audiovisual experimental amplia o repertório possível de montagens entre som e imagem em movimento, e consolida a diversidade formal ao longo das décadas. No período analisado neste artigo, há uma diversificação de abordagens que dificulta estabelecer fios condutores tão explícitos como haviam sido os da visual music, nos anos 1920 e 1930, ou os da performance dos shows de luz, nos anos 1960 e 1970. Essa diversidade será explorada, no presente artigo, por meio da análise de obras importantes da época. O texto se divide em dois momentos: um relato sobre os diálogos entre as experiências de mistura entre música pop e projeção que, nos anos 1980, vêm a constituir-se em uma abordagem da performance multimídia segundo acepções da ópera; uma leitura crítica de alguns trabalhos significativos dessa vertente.

\section{Vanguardas e pop no palco: óperas dos anos 1970 aos anos 1990}

O cruzamento entre as poéticas ao vivo e a música pop, e a presença no palco de toda sorte de gêneros como dança, teatro, textos poéticos - ou narrativos - e artes visuais, costuma resultar em experiências bastante férteis em termos de experimentação. Da relação entre as artes em cena e das escolhas formais levadas ao palco por cada uma delas, um todo incomum 
pode emergir. Esses eventos podem ser considerados tributários da ópera por seu aspecto intermidiático, entendida a intermedia como operação intersemiótica dos signos de um campo da arte, ao se apresentarem transbordando seus limites e cruzando linguagens. A visual music é um exemplo de um meio se mesclando ao outro. A configuração multimídia dos shows, ou seja, com diversas artes acontecendo simultaneamente, é outro aspecto formal a aproximar a performance e a ópera e, finalmente, a valorização da música como guia do trabalho. Como cada um dos campos de criação se coloca e a relação estabelecida com os demais durante a apresentação é um dos aspectos a singularizar ópera e performance. Há algum protagonismo de um campo, como cenografia, luz, narrativa, etc? Um campo se destaca em relação aos outros?

Há controvérsias sobre a data das primeiras óperas, entre o final do século XVI e o início do XVII. Sobre o local inexistem dúvidas, a Itália de hoje. Nesses cinco séculos de existência, a quantidade de árias e cenas se modificaram. Em oposição à ópera séria, a ópera bufa contemplou o gosto popular no século XVIII, mas era ainda voltada à elite. Em 1849, Richard Wagner, no artigo Esboços da Obra de Arte do Futuro, procura sintetizar o que vem a ser a ópera: "obra de arte total”, o Gesamtkunstwerk. Os recursos dramáticos e o suporte técnico necessário para envolver o público são descritos. Segundo Wagner (1849), o crescimento da potência dramática da ópera é valorizado pela multiplicidade de artes e pela afetação de uma arte por outra, devido à sua execução em conjunto. Desse modo, cada uma das artes e o todo alcançam outra potência: "Assim, a ilusão das artes plásticas transformará a verdade em Drama: o artista plástico estenderá as mãos para o dançarino, para o mímico, se perderá neles e, assim, se tornará ele mesmo mímico e dançarino" (ibidem, p. 7).

Richard Wagner contribui de forma definitiva para uma arte do futuro a partir da união de arquitetura, música, pintura, poesia e dança, propondo uma experiência de arte total. Em Wagner, a ópera tem por horizonte a valorização do drama e, como acima citado, o apagamento dos meios de enunciação. Busca-se a supressão da realidade por um mergulho no drama, então capaz de proporcionar ao público se descolar "do confinamento do auditório, e viver e respirar apenas o trabalho de arte que se parece com a Vida em si" (ibidem, p. 6). Esse objetivo foi cumprido pela ópera e ainda é meta de certos espetáculos e filmes contemporâneos. É essa intermedialidade que aproxima a ópera da performance multimídia dos anos 1970 e 1980, 
assim como da performance audiovisual contemporânea, em que pesem diferenças que serão observadas oportunamente.

Wagner se apresentava nas capitais do mundo, merecendo de Charles Baudelaire defesa inconteste. A apreciação de Baudelaire encontra na obra de Wagner, entre outros méritos, um jogo de correspondência entre artes que dá continuidade a uma tradição de diálogo entre som e imagem em movimento, o que culmina em experiências como Prometeus, no início do século XX, e nos desdobramentos que surgirão a partir de então, conforme é discutido de forma mais detalhada no livro Audiovisual ao vivo: tendências e conceitos ${ }^{1}$. Baudelaire afirma em mais de uma passagem a relação entre sons e cores, um dos problemas centrais deste campo de pesquisa².

Aqui não será ridículo argumentar a priori, sem análise e
sem comparações, pois o que seria verdadeiramente sur-
preendente seria que o som não pudesse sugerir a cor, que
as cores não pudessem dar a uma ideia de uma melodia, e
que o som e a cor fossem impróprios para traduzir ideias,
sendo as coisas sempre exprimidas por uma analogia recí-
proca, desde o dia em que Deus criou o mundo como um
complexa e indivisível totalidade (BAUDELAIRE, 1861, p. 27).

O destaque aqui concedido a Wagner e as colocações de seus contemporâneos ao impacto de sua obra devem-se a sua valorização da experiência sensorial, ao idealizar um espetáculo atento à relação entre as artes em jogo. Essa dimensão sensorial o aproxima do tema da sinestesia, que é um fio condutor recorrente para pensar os elos entre os diferentes tipos de manifestação intersemiótica. Mesmo que a experiência sinestésica mais direta não esteja sempre presente nos cruzamentos de sentido das linguagens ao vivo, o elemento multissensório resultante é algo que une ópera e performance multimídia.

Os textos eram caros aos monumentais dramas de Wagner, assim como a inovadora exploração do leitmotiv, mas, ao construir na Alemanha um teatro em Bayreuth (1876) para acolher anualmente suas óperas, tinha no horizonte

1 Cf. BASTOS, M.; MORAN, P. Audiovisual ao vivo: tendências e conceitos. São Paulo: Intermeios, 2020.

2 Em artigo de título Uma arqueologia da Performance Audiovisual, apresentado por Marcus Bastos e Patrícia Moran no $9^{\circ}$ Encontro Internacional de Grupos de Pesquisa - Convergências entre Arte, Ciência, Tecnologia e Realidades Mistas, é desenvolvido de forma mais ampla o tema da relação entre cores e som, com ênfase num resgate da história dos órgãos de cor, instrumentos musicais modificados que associam as notas do teclado a uma tira de papel ou emissão luminosa colorida. Ao remeter às passagens de Baudelaire sobre as relações entre cor e som, o texto indiretamente refere-se a essa longa discussão que, todavia, não faz sentido resgatar neste contexto, pelo enfoque adotado neste artigo. 
uma preocupação valorizada por novos meios, como a de criar condições técnicas ideais para acolher os meios e proporcionar uma experiência de imersão ${ }^{3}$. Hoje, artistas e pesquisadores, como Chris Salter, Steve Dixon, Randall Packer e Ken Jordan, reconhecem na obra arquitetônica e musical de Wagner um antecedente de certos aspectos da performance audiovisual contemporânea. Para alcançar a afetação multissensorial e assegurar a separação entre o mundo real e o cênico, empreendeu esforço considerável para criar um espaço arquitetônico especialmente voltado para o melhor acolhimento possível dos recursos expressivos e, simultaneamente, o isolamento do público do ato de criação da ópera, a sua transparência, ou seja, não se dar a ver as marcas de criação. O teatro de Bayreuth é entendido por Salter (2010, p. 2) como uma tecnologia:

[...] um design de mídia cuidadosamente coreografado, conforme um espaço arquitetônico especialmente projetado para se criar uma total imersão nos sentidos do espectador, literalmente varridos (sweeping) em uma vertigem hipnótica, o que Albert Goldman, estudioso e editor da obra de Wagner, chama de teatro do narcótico.

O autor e artista Chris Salter (2010) procura, em Entangled: technology and the transformations of performance, estabelecer algumas das práticas, das pesquisas de materiais e técnicas, acumuladas ao longo dos anos. Muitas delas, como o teatro idealizado e levado adiante por Wagner, definiam um lugar para o público e estabeleciam uma relação entre os meios. Vale lembrar que o próprio teatro de Bayreuth contará, após ser inaugurado, com a contribuição do arquiteto Adolphe Appia para elaborar a iluminação.

Salter (2010) e Dixon (2007) aliam sua investigação artística à inclusão do público, à explicitação dos meios de produção. Salter (2010) visa aos sentidos, indaga, em suas instalações aos sentidos, o que e como se percebe. Já Dixon (2007, p. 41-42) tem na multimídia seu campo criativo. Como ator e diretor, ele faz de suas peças eventos em que se mesclam sincronicamente atores de corpo presente e em projeção, evidenciando-se os aparatos mediadores e a chamada do público a perceber o espetáculo como tal. Assim,

3 O termo imersão ganhou centralidade no final do século XX, em função de equipamentos e poéticas que prometem um mergulho no trabalho, além do estado de concentração no ciberespaço e em games. Aos poucos a discussão se amplia, e Janet Murray nos lembra tratar-se da leitura de um processo imersivo. A inclusão de meios e processos tradicionais, como a literatura, não subtrai à imersão sua relação com pesquisas voltadas para a afetação multissensorial do público e, em diversas ocasiões, a situação é propiciada pela técnica. 
as tendências mais recentes da performance deixam entrever feedbacks entre suas práticas e as experiências dos pioneiros, através de dobras e frestas.

A ópera, no geral, abriga amplo leque de formas. Acolhe eventos simultâneos e plurais, em presença. Sua abertura enseja potencial fonte de invenção, dadas as possibilidades de arranjos formais acionados pela quantidade de expressões poéticas e mídias em curso simultaneamente. O leque de combinações possíveis entre artes - em um palco — é bastante amplo, resultando na ópera pop, que estabelece fios de continuidade com a ópera, mas rompe num aspecto central: ao passo que a ópera mantém os rituais tradicionais, a ópera pop almeja uma difusão ampla, desdobrando os ideais dos anos 1960 de dissolução das fronteiras entre linguagens, entre arte e vida, e entre erudito e popular. Cada uma dessas expressões musicais tem o seu lugar: esta comparação não visa a estabelecer uma medida em termos de qualidade, mas a trazer uma distinta abordagem poética, principalmente musical. Recupera-se uma ópera popular voltada a um público massivo, movimento distinto da ópera bufa ou cômica, que se aproxima de temas populares.

Além disso, a ópera tem uma estrutura formal bastante definida, repetindo padrões e formas de organização que se consolidam ao longo das décadas, tornando-se marcas distintivas do gênero e pertencimento a uma tradição. Em meio à variedade composicional, há um pano de fundo que se repete, consolidando características definidoras. A ópera contemporânea rompeu com estruturas rígidas e extrapola o virtuosismo vocal e musical. Philip Glass privilegia espetáculos imersivos, voltados à criação de fábulas, mas, em espetáculos como Einstein on the beach, as pausas dos cantores e dançarinos, a suspensão de segundos da ação, são uma espécie de interpelação ao público, evidenciando o espetáculo como construção. A monumental obra de Jocy de Oliveira musicalmente é iconoclasta, não segue o repertório tradicional, inventa, mesclando personagens e situações fantásticas e localizáveis no cotidiano, em complexa estrutura disruptiva distante do pop.

A ópera pop adota poucos padrões. Ela elege seus materiais narrativos e plásticos a partir das necessidades específicas de cada obra. Entre fios de continuidade e ruptura, esse olhar para os formatos que surgem na sinergia entre erudito e popular na ópera pop será tomado como exemplo de análise mais adiante, quando o texto tratar das experiências de artistas como Arrigo Barnabé, José Roberto Aguilar e Décio Pignatari (neste caso, em obra que se diferencia das anteriores, pois, ao invés da sinergia com o pop, explora os desdobramentos das poéticas de vanguarda na literatura e na música). 
É a partir do tratamento e do arranjo dos elementos cênicos, do volume de materiais e da ordenação de temas descontínuos que se estruturam os trabalhos. Um amplo leque de circuitos e formas cabe na ópera. As obras que serão analisadas a seguir exploram alguns desses aspectos, ilustrando o jogo de proximidade e distância entre a ópera, especialmente a ópera pop, e a performance audiovisual contemporânea. São obras de transição, em certo sentido, pois exploram elementos da multimídia e da performance, conforme elas se constituíram nos anos 1960, e antecipam modos de organização das linguagens no palco que vão aparecer de forma mais explícita com os VJs.

\section{Colagens pop tropicais}

Antes de seguir com as análises, é importante salientar um desafio intrínseco à escrita crítica sobre os eventos em presença. Os autores deste ensaio compareceram a muitas das apresentações analisadas, experimentando o impacto dos trabalhos, tendo uma relação vívida com estes. No entanto, em muitos casos, restaram registros exíguos. Sendo a memória imprecisa, como garantir a coincidência entre as lembranças e os eventos em si? Este desafio perpassa a pesquisa da performance, com seu conjunto de trabalhos efêmeros cujas obras são acontecimentos. É possível recorrer a entrevistas com os artistas, fotos, teses, pesquisas em periódicos pela internet e eventuais registros em vídeo das obras, visando a minimizar problemas. Além disso, a presença do crítico nas obras comentadas é importante nesses casos, pois se trata de trabalhos em que a dimensão do acontecimento é central à poética em jogo. Escrever sobre trabalhos presenciais apenas por meio de documentação suprime a dimensão mais importante da obra. Por isso, o ideal é evitar escrever sobre obras que não foram experimentadas ao vivo, salvo exceções em que a importância e a riqueza da documentação justifiquem uma incursão sobre o trabalho.

Em Avant-garde Performance - Live Events and Electronic Technologies, Gunther Berghaus discorre sobre o desafio metodológico enfrentado pelos teóricos e críticos voltados para o estudo de eventos efêmeros:

Ainda que eu mesmo tenha sido um observador interessado de muitas das performances de vanguarda do último terço do século XX, eu não me consideraria necessariamente uma testemunha confiável e objetiva destes eventos. Os caprichos do gosto e da predileção pessoal, das modas e coqueluches temporárias, assim como as limitações de acessibilidade, verba para viagem, agendas, etc., 


\begin{abstract}
determinaram o que eu poderia ou gostaria de ver. Isto, inevitavelmente, significou que eu perdi algumas grandes oportunidades; mas mesmo espetáculos que eu consegui ver começaram a esmaecer em minha memória depois de dez, quinze anos. Por isso, todas as performances discutidas neste volume tiveram de ser revisitadas pelo exame de relatos escritos ou visuais recuperados em arquivos, bibliotecas, museus e coleções particulares. Isto incluiu, em primeira instância, documentos deixados pelos artistas, como textos, partituras, projetos cenográficos, projetos, artigos, entrevistas, etc. [...] Desnecessário dizer, registros deste tipo demandam avaliação cuidadosa, já que tendem a ser altamente seletivos e determinados pelos interesses da pessoa que os produz (ou preserva) (BERGHAUS, 2005, Kindle Edition, LOC 215 de 10076).
\end{abstract}

Soma-se a essa dificuldade o fato de estarmos tratando de obras levadas ao público há algumas décadas, em um momento de circulação dos artistas por meios de criação e espaços de difusão. O pertencimento dos artistas a mais de um circuito de circulação da arte marcará essas obras. O tropicalismo, por exemplo, se faz presente na obra de alguns dos artistas. Pródigo em unir referências eruditas da arte e filosofia, assim como repertórios da cultura popular, o tropicalismo é adotado pela poesia concreta, apropriando-se das artes visuais e da comunicação de massa, como tema e forma presentes no repertório de algumas das performances, como veremos. O artista visual José Roberto Aguilar é um nome exemplar. Integrara, com Jorge Mautner e José Agrippino de Paula, a ação artístico-literária Kaos, tendo Nietzsche, Lao-Tse e o rock como referências temáticas para suas colagens multimídia. A filiação de Aguilar ao pensamento de Mautner é de toda uma vida. Do colégio até hoje, dividem valores e entendimento da arte. Aguilar é o líder do grupo da Banda Performática: “Um conjunto de rock sempre será um conjunto de rock: desencadeador, deflagrador de ética libertária. Música da sociedade pós-industrial, música democrática, popular" (MAUTNER, 1976, p. 15). Jorge Mautner externa o lugar do rock no final dos anos 1960 e início de 1970. Essas performances audiovisuais multimídia, óperas pop, são fruto da expansão da classe média urbana e do estabelecimento da cultura urbana renovada pelo processo de industrialização.

O tropicalismo também se inscreve nessas mudanças ao recuperar, através de manifestações como a poesia concreta, a antropofagia e o ideário oswaldiano. Aguilar, integrante transversal da Tropicália, adota o modernismo no seu aspecto formal de carnavalização. O título de 
sua ópera rock O circo antropofágico (1977) é um tributo ao Manifesto Antropofágico de 1928. Os temas e posturas revisitados e inventariados no tropicalismo conquistam, com Aguilar, uma versão de acontecimento descolado do rendimento musical demandado pela indústria. Enfim, Aguilar se transveste em performer, idealizador de uma série de eventos em que prevalecem a alegoria e a paródia em espetáculos colagem, recurso largamente adotado pelo tropicalismo, evidente em músicas como Domingo no Parque, de Gilberto Gil, e Alegria, Alegria, de Caetano Veloso. O povo, a cidade, o excesso de informações propiciado pela comunicação massiva, enfim, as músicas compõem um retrato de país com imagens incompletas. Colagem alegórica adotada por nosso performer.

Uma profusão de imagens projetadas, de monitores e televisivas, compõe a cena e a dramaturgia da performance audiovisual ópera do terceiro mundo, de 1979. Foi montada no Centro Georges Pompidou, a convite do curador e pesquisador de performance Jorge Glusberg, para as Journées Interdisciplinaires sur L'art Corporel et Performances. Os repertórios de Aguilar são justapostos sincrônica e diacronicamente. A apresentação mescla dois telões: um com uma cerimônia do Laos e outro com um ritual de candomblé gravado em Itaparica. Aos rituais religiosos representativos do Brasil profundo e da cultura popular, segue-se um líder despótico com faixa presidencial, de óculos e com revólver em punho. A imagem é um apelo direto da arte contra a ditadura. O trabalho estava sendo apresentado em Paris, corajosa denúncia ao mundo expressa através das falas, dos corpos e da profusão de recursos audiovisuais acionados.

Há monitor de TV ligado no palco, exibindo o debate do primeiro dia do encontro. A cenografia e a encenação remetem a rituais e as velas à tradição cristã, enquanto os performers pronunciam aos berros em português, espanhol, francês e inglês as frases: "Eu sou América Latina" e "Não, eu não sou América Latina" (MEIRELLES, 2011, p. 31), uma frase desconstruindo a outra. A ambivalência do texto dito de forma mecânica pelo performer é confrontada com a quantidade de informações e estímulos de presença, como as velas, compondo-se a Ópera do terceiro mundo, de Aguilar, como resultado de uma montagem por estilhaços. Ismail Xavier e Celso Favaretto analisam a figura alegórica no cinema e no tropicalismo contemporâneos de Aguilar. As figuras alegóricas deslocam por si só as imagens evocadas, representam figurativamente mais de um significado, adotando como ponto de partida o duplo sentido, a implosão da unidade, em diálogo 
com a visualidade da montagem. A estrutura multimídia da obra acentua a potência espraiada de cada uma das mídias, acentuando a incongruência da profusão de imagens deslocadas em ação. Na obra Ópera, essa estrutura emerge pela colagem presente nas frases ditas, nas figuras projetadas no telão e no monitor, pela duplicidade significante entre as mídias. A América Latina é aqui fraturada, potência na cultura e violência na política, fruto da somatória dessas ações.

\section{Violências urbanas entre séries dodecafônicas}

Uma das obras que marca a paisagem estética dos anos 1980 é Clara Crocodilo, de Arrigo Barnabé. O disco que deu origem ao show é um dos marcos da música pop brasileira, em sua tentativa de incorporar em seu repertório tanto recursos da música instrumental de vanguarda quanto diálogos intersemióticos os mais diversos, especialmente as histórias em quadrinhos. Essa abordagem está ligada a uma mudança da cena urbana e à consolidação de nova geração pop na época, mesclando, além da experimentação musical de vanguarda, o rock e a cultura urbana como tema. 0 percurso de Arrigo Barnabé evidencia a formação de seu repertório por meio de cenários culturais e acadêmicos, acumulados e sobrepostos em sua obra:

O processo até tornar-se músico profissional, todavia, demandou bastante tempo. Em 1970, Arrigo Barnabé foi para São Paulo estudar para o vestibular de Engenharia Química; acabou desistindo e fez cursinho para Arquitetura (CASSOLI, 2001, p. 110). O colega Luiz Gê, mais tarde autor de ilustrações das capas de seus dois primeiros LPs e seu parceiro em Tubarões voadores, levou a uma exposição de história em quadrinhos no Museu de Arte de São Paulo (MASP). A partir daí, Arrigo começou a "curtir história em quadrinhos", linguagem decisiva na criação de "Clara Crocodilo" e de outras composições. Ingressou na Faculdade de Arquitetura e Urbanismo (FAU) da Universidade de São Paulo (USP), uma faculdade onde conviviam pessoas que se interessavam por diversas artes, fotografia, cartum, música, "todo mundo lá misturado" (GARCIA, 2015, pp. 80-81).

É esse investimento no diálogo entre artes que fará com que o show Clara Crocodilo explore um repertório mais amplo de elementos cênicos. Há uma lógica de buscar o engajamento do público por recursos que extrapolam a música, que não é estranha ao universo da música pop, pelo menos desde os shows das bandas de música psicodélica e hard rock dos anos 1970. Mas, 
em Clara Crocodilo, essa mistura de elementos musicais e cênicos acontece com um sentido completamente diferente, mais ligado à tradição performática das vanguardas históricas, com sua atitude iconoclasta e irônica.

De certa forma, há até um exagero retórico nos modos como as músicas são apresentadas, com uma ênfase na gestualidade irônica, num certo distanciamento calculado e provocativo, e numa fricção entre os elementos em palco, o que leva ao estranhamento. Há um elemento de violência em jogo, ainda que Luiz Nazário o considere uma agressividade apenas aparente, na medida em que se trata de um exercício bem-sucedido de traduzir em termos cênicos e musicais a violência do cotidiano:

\begin{abstract}
Nesse sentido, a música de Arrigo apenas parece agressiva: de fato, limita-se a tornar transparente a agressividade da realidade que emoldura - o processo de industrialização total por que passa a América Latina: internacionalizada e urbanizada em seus pontos nevrálgicos, ela só pode manter o ritmo de crescimento sobre a ruína de suas tradições. O sonho agrário do populismo é desfeito pela realidade tecnológica, como um castelinho de areia que se dissolve, engolido pela onda. As novas gerações são formadas por mutantes, que tentam sobreviver arrastando-se do centro para a margem, da cultura para a natureza (NAZARIO, 1983, p. 29-34).
\end{abstract}

Esse aspecto de montagem espacial que agrupa os elementos que compõem o jogo de cena no show Clara Crocodilo está ligado a um aspecto central da obra, que é seu diálogo com a ópera. Apesar de a literatura especializada nem sempre tocar no assunto, preferindo enfatizar as conversas que Arrigo Barnabé estabelece com a música instrumental de vanguarda, conforme a Wikipedia (s/d), a revista "Rolling Stone classificou o disco como uma ópera pop cujo pano de fundo é a vida degradada nas cidades". Essa proximidade com a ópera e o caráter de montagem dos elementos no palco conectam o show Clara Crocodilo com o modo de trabalhar as linguagens da poesia concreta, o que aproxima as propostas de Arrigo Barnabé da experiência de TemperaMental, que será analisada a seguir.

\title{
Desvios intersemióticos da palavra
}

Apesar de ter sido lançada em disco em 1993, TemperaMental, a obra interativa de Décio Pignatari, em parceria com Livio Tragtenberg e Wilson Sukorski, se insere nestas inquietações poéticas que movimentaram os anos 1980 no trânsito entre as performances audiovisuais e a ópera. Ela difere das obras 
apresentadas até aqui em dois sentidos, permitindo expandir ainda mais o repertório de experimentações a que este texto se dedica. Ao contrário da colagem multimídia e de intervenções como as de Aguilar, a obra de Pignatari busca articulações lógicas e qualitativas entre os elementos de linguagem que movimenta. E, diferentemente do trânsito entre as linguagens pop e experimental que aparece nas obras de Arrigo Barnabé e Aguilar, TemperaMental desdobra as pesquisas da vanguarda poética e musical, levando adiante os diálogos entre palavra e som que marcaram a poesia concreta desde seus primórdios.

O diálogo intersemiótico na poesia concreta filia-se a uma tradição de montagem estreitamente relacionada às reflexões eisensteinianas sobre a semelhança de procedimentos entre o ideograma e a montagem intelectual. A relação qualitativa e dialética entre os elementos articulados pela montagem converge num amálgama em que o resultado é maior do que as partes envolvidas. Isto aparece textualmente no texto Poesia concreta, de Augusto de Campos (1975, p. 45), em que ele apresenta como a poesia concreta explora "o uso substantivo do espaço como elemento de composição", numa "dialética entre olho e fôlego, que, aliada à síntese ideogrâmica do significado, cria uma totalidade sensível verbivocovisual".

Em TemperaMental, um dos principais focos de tensionamento poético é a fricção entre a palavra e suas sonoridades. Em Peirce Poem, por exemplo, o texto oscila entre o canto e a fala. A composição, construída em torno da formulação "chaos / peirce poem" escande as possibilidades de vocalização desse par central, que se desdobra em diversas combinações, num equivalente sonoro dos efeitos de leitura múltipla provocados pela espacialização da palavra na página inventada pela poesia concreta.

Em Interesse, esse diálogo intersemiótico entre palavra e som fica em segundo plano, em favor de uma estratégia declamatória. Os opostos formulados pela letra ("Na arte interessa o que não é arte", "Na poesia, interessa o que não é poesia", "Na história, interessa o que não é história”, "etc") vão sendo recitados de forma ríspida, às vezes como num discurso, às vezes num grito um pouco mais pronunciado. Essa camada textual mais monocórdica contrasta de forma radical com os passeios quase jazzísticos de piano que, todavia, dispara notas e acordes atonais, em contraste com interferências de percussão eletrônica de acento quase industrial. TemperaMental se aproxima da tradição intersemiótica em análise neste texto a partir de seu cerne, pois, 
entre as obras examinadas, é aquela que busca de forma mais estrutural o diálogo entre linguagens.

\section{Conclusão}

A análise das obras apresentadas no presente artigo procura evidenciar como a terminologia sobre ópera e multimídia, e seu discurso crítico, é bastante heterogênea, e como as particularidades de cada trabalho apontam diferentes ênfases nos arranjos presentes. Mesmo assim, certas preocupações parecem persistir, especialmente em torno de problemas ligados à montagem entre expressões artísticas, que ora aparecem em formulações relativas ao diálogo com o espaço do palco, ora aparecem em formulações sobre o diálogo entre corpo e tela, ou entre palavra e som. Em consequência, é possível concluir que esse conjunto específico de obras não suscita grandes alargamentos semânticos do campo conceitual construído em torno das linguagens audiovisuais experimentais, dialogando com categorias de análise já consolidadas na bibliografia especializada, por meio de conceitos como intermídia, multimídia, colagem, montagem e montagem espacial.

Há, sobretudo, uma recontextualização desses termos, que ganham novos sentidos conforme são usados para pensar obras que operam na esfera do ambiente e do acontecimento. Talvez o conceito de ambiente mereça maior exploração neste contexto, um desafio para possíveis pesquisas futuras, já que o termo acontecimento já foi bastante discutido em outras oportunidades, e vai aparecer como um dos fios condutores do livro que os autores deste texto finalizaram recentemente abordando temas, conceitos, arqueologias e tendências da performance audiovisual contemporânea.

A principal conclusão deste percurso é que a riqueza das obras que compõem esse universo de diálogo entre as práticas experimentais mais consolidadas e o campo emergente da performance audiovisual apenas começou a ser explorada, demandando esforço conceitual de maior fôlego, a ser desenvolvido em futuras investigações. Como resultado, seria necessário ampliar esse esforço, a partir do reconhecimento de que os vetores apontados pelas obras são mais heterogêneos do que qualquer possível corpo teórico organizado em torno deles. Os anos 1980 se mostram como uma época chave desse percurso, na medida em que começam a aparecer experiências que promovem o encontro entre a música e a projeção no palco, antecipando no Brasil expressões do chamado live cinema e da performance audiovisual. 
Marcus Vinicius Fainer Bastos é professor da PUC-SP. Publicou os livros Audiovisual ao Vivo: tendências e conceitos (com Patricia Moran, Intermeios, 2020), Limiares das Redes (Intermeios, 2014) e Cultura da Reciclagem (Noema, 2007, ebook), além de organizar Audiovisual Experimental. Arqueologias, diálogos, desdobramentos (com Natalia Aly, Pontocom, 2018), Cinema Apesar da Imagem (com Gabriel Menotti e Patricia Moran, Intermeios, 2016) e Mediações, Tecnologia, Espaço Público: panorama crítico da arte em mídias móveis (com Lucas Bambozzi e Rodrigo Minelli, Conrad, 2010).

marcusbastos@pucsp.br

Patricia Moran Fernandes é professora livre docente do CTR da ECA/USP. É mestre em Comunicação Social pela UFRJ e doutora em Comunicação e Semiótica pela PUC/ SP. Dirigiu documentários e ensaios experimentais, conquistando prêmios nacionais e internacionais. Coordenou a coleção de livros do CINUSP, editando dois volumes. Organizou pela Intermeios Cinema Apesar da Imagem (com Marcus Bastos e Gabriel Menotti, 2016) e pela Iluminuras Cinemas Transversais (2016). Em 2020 lançou Audiovisual ao vivo. Tendências e Conceitos, com Marcus Bastos. Atualmente edita a Significação: Revista de Cultural Audiovisual. Pesquisa poéticas experimentais e ao vivo.

patriciamoran@usp.br

Contribuições de cada autor: Marcus - fundamentação teórica e conceituação, escrita - primeira redação, revisão e edição, investigação de campo, análise formal do corpus; Patrícia - fundamentação teórica e conceituação, escrita - primeira redação, revisão e edição, investigação de campo, análise formal do corpus.

\section{Referências}

BAUDELAIRE, C. Richard Wagner e Tannhäuser em Paris. (1861). In: LOPES, E. M. T. (org. e trad.). Belo Horizonte: Autêntica, 2013.

BASTOS, M.; MORAN, P. Uma arqueologia da Performance Audiovisual. In: $9^{\circ}$ Encontro Internacional de Grupos de Pesquisa. Convergências entre Arte, Ciência, Tecnologia e Realidades Mistas. São Paulo: Unesp, 2019.

BERGHAUS, G. Avant-garde Performance. Live Events and Electronic Technologies. Londres: Palgrave Macmillan, 2005. Loc 215 de 10076. 
CAMPOS, A. de; CAMPOS, H. de; PIGNATARI, D. Teoria da Poesia Concreta. Textos Críticos e Manifestos 1950-1960. São Paulo: Livraria Duas Cidades, 1975.

DIXON, S. Digital performance. A history of new media in theater, dance, performance art, and installation. Cambridge/London: The MIT Press, 2007.

FAVARETTO, C. Tropicália. Alegoria, Alegria. São Paulo: Kairos, 1979.

GARCIA, W. Clara Crocodilo e Nego Dito: dois perigosos marginais? In: revista Antíteses, v. 8, n. 15, p. 10-36. Londrina: UEL, jan./jun. 2015.

KITTLER, F. World-Breath. On Wagner's Media Technology. In: The truth of the technological world. Essays on the genealogy of presence. Stanford: Stanford University Press, 2013.

MAUTNER, J. Fragmentos de um sabonete. Rio de Janeiro: Ground Informação, 1976.

MEIRELLES, L. C. J. 3 Óperas de José Roberto Aguilar e algumas referências da arte conceitual dos anos 70. São Paulo: ECA/USP, 2011. Dissertação de Mestrado em Artes Visuais.

'Óperas conceituais' dos anos 70 de José Roberto Aguilar. In: $19^{\circ}$ Encontro da Associação Nacional de Pesquisa em Artes Plásticas. Entre Territórios. Cachoeira (BA): UFRB, 2010.

MORAN, P. A noção de tempo na performance como acontecimento. Palestra na Ephemeral Expanded Lecture Series. Porto: FLUP, 2015.

. A montagem dos VJs: entre a estimulação ótica e a física. In: DOMINGUES, D.; VENTURELLI, S. Criação e Poéticas digitais. Caxias do Sul: EDUCS, 2005.

NAZARIO, L. O universo de Clara Crocodilo. In: Da natureza dos monstros. São Paulo: Editora do Autor, 1983.

RAJEWSKY, I. O. Intermediality, Intertextuality, and Remediation: A Literary Perspective on Intermediality. Journal: Intermediality History and Theory of the Arts, Literature and Technologies. Intermediality 6 (2005): 43-64. Montreal: Université de Montréal, Université Laval e UQÁM. Disponível em: <https://www.erudit.org/en/journals/im/2005n6-im1814727/1005505ar/>.

SALTER, C. Entangled. Technology and the transformation of performance. Cambridge/ London: The MIT Press, 2010.

SARMENTO, F. José Roberto Aguilar. 1960-1989. Introdução: Nelson Aguilar; Textos: Solange Lisboa. São Paulo: GPA Projetos Culturais, 2013.

WAGNER, R. Outlines of the Artwork of the Future. In: PACKER, R.; JORDAN, K. (ed.) Multimedia. From Wagner to virtual reality. New York. London: W.W. Norton \& Company, 2002.

WIKIPEDIA. Disponível em: <https://pt.wikipedia.org/wiki/Clara_Crocodilo\#cite_note-RolSton-4>. S/d. 